\title{
Fatty acid dietary intake in the general French population: are the French Agency for Food, Environmental and Occupational Health \& Safety (ANSES) national recommendations met?
}

\author{
Jessica Tressou $^{1 *}$, Philippe Moulin ${ }^{2}$, Bruno Vergès $^{3}$, Céline Le Guillou ${ }^{4}$, Noémie Simon ${ }^{4}$ \\ and Stéphane Pasteau ${ }^{5}$ \\ ${ }^{1}$ UMR MIA-Paris, AgroParisTech, INRA, Université Paris-Saclay, 75005 Paris, France \\ ${ }^{2}$ Fédération d'endocrinologie, Hôpital Louis Pradel GHE, Université Lyon 1, UMR INSERM CARMEN 1060, Lyon, France \\ ${ }^{3}$ Service Endocrinologie-Diabétologie, CHU de Dijon, Université Bourgogne Franche-Comté, INSERM LNC UMR866, \\ 21000 Dijon, France \\ ${ }^{4}$ Terres Univia, 75008 Paris, France \\ ${ }^{5}$ Phasme, 75006 Paris, France \\ (Submitted 19 May 2016 - Final revision received 24 October 2016 - Accepted 2 November 2016)
}

\section{Abstract}

Quantity and quality of fatty acids (FA) in diet influence CVD risk. Consequently, health authorities promote recommended dietary intakes for FA, looking for optimal intakes in a primary prevention of CVD perspective. In parallel, a few data are available detailing intakes in national populations. The objective of the present study was to perform a large analysis combining the data of the French National Survey INCA 2 on food consumption performed in 2006 and 2007, and the nutritional content of food consumed in France updated in 2013 by the French Information Centre on Food Quality, to explore in details the FA intakes in French adults using the most recent available data. To compare the discrepancies in the observed intake levels with the French recommended levels, a weighted fat adherence score was built combining intakes of the different FA. Individual scores were computed in relation to official recommendations, and potential explanatory factors were identified. These data show that SFA intakes are persistently higher than national recommendations, combined with low intakes of MUFA and PUFA, particularly long-chain $n$-3 FA. Only $14.6 \%$ of the French population met DHA intake recommendation, $7 \cdot 8 \%$ for EPA and $21 \cdot 6 \%$ for SFA. This situation remains unfavourable in terms of primary prevention of CVD. Consuming fish and other sources of $n-3$ FA, living in the south of France, being female, having a higher education level, and low alcohol consumption were associated with a healthier fat adherence score.

\section{Key words: Fatty acid intakes: Recommended dietary intakes: Cardiovascular prevention: Fat adherence score}

Among the pleiotropic effects of fatty acids (FA), CVD prevention is the most documented one, with recent results from clinical trials providing new insights into the integrative effects of FA in CVD prevention ${ }^{(1-4)}$. In addition, the intakes of several FA as risk factors is subject to continuous evolution, including the important aspect of their replacement by other nutrients ${ }^{(5-9)}$. Consequently, it is important to periodically re-assess FA intakes in different populations ${ }^{(10-13)}$.

As most international and national organisations, The French Agency for Food, Environmental and Occupational Health \& Safety (ANSES) regularly issues statements regarding dietary recommendations for major nutrients such as fats. The last updated recommendation establishing French population recommended dietary intakes (RDI) for FA in 2010 looks for optimal intakes and optimum health conditions in the general population, in a primary prevention of CVD perspective ${ }^{(14)}$.
However, accurate data combining updated food composition and recent evolution in food consumption in large populations are scarce, even in countries such as France. In addition, the evolving factors that may drive FA intakes have not been deeply studied. This prompted us to perform a large analysis combining the set of national data publicly available on food consumption (the French National Survey INCA 2 performed in 2006 and 2007) and the nutritional content of food consumed in France updated by Ciqual (the French Information Center on Food Quality) in 2013.

The main objective of our study was to explore fat intakes in French adults using the most recent and accessible data, in order to identify the contributions of key food categories and discrepancies in the observed intake levels. For this purpose, we built a weighted fat adherence score combining the intakes of different FA and their importance in terms of CVD risk

Abbreviations: ALA, $\alpha$-linolenic acid; ANSES, French Agency for Food, Environmental and Occupational Health \& Safety; EIEA, energy intake excluding alcohol; FA, fatty acid; LA, linoleic acid; RDI, recommended dietary intake.

* Corresponding author: J. Tressou, fax +3314408 7276, email jessica.tressou@agroparistech.fr 
prevention. Individual scores were computed in relation to the recommended French daily intakes, looking for potential explanatory factors

\section{Methods \\ Description of data}

The statistical analysis involved a combination of INCA 2 data with data on the nutritional composition of basic food products, drawn from ANSES Ciqual 2013 database (https://pro.anses.fr/ TableCIQUAL/).

Participants in the INCA 2 study were selected using a three-stage random probability design stratified by region of residence, size of urban area and population category (adults or children). This design was summarised into sampling weights provided for each surveyed individual representing the frequency in the entire French population. Each participant was asked to complete a 7-d food diary as well as other questionnaires on anthropometric and socio-economic factors. Food items declared were subsequently categorised into 1305 'as consumed' food items for which the nutritional content was either available in the Ciqual database or could be deduced through their recipe. Following the methodology recommended by ANSES (cf. https://www.data.gouv.fr/fr/datasets/donneesde-consommations-et-habitudes-alimentaires-de-letude-inca-2-3/), results are presented for a weighed representative sample of the French population (2624 adults)

INCA 2 data also included some information about dietary supplements that participants may have taken, but this was a very infrequent practice in the studied sample (and in general in France), particularly for FA intakes, and therefore this was ignored with the exception of margarines supplemented with $n-3$ FA.

The following nutrients were considered:

- Total energy intake excluding alcohol (EIEA), total energy intake, alcohol intake, total fat and cholesterol.

- Total SFA, with details of butyric acid (4:0), caproic acid $(6: 0)$, caprylic acid $(8: 0)$, capric acid $(10: 0)$, lauric acid (12:0), myristic acid (14:0), palmitic acid (16:0) and stearic acid (18:0); lauric, myristic and palmitic acids were summed up as specific SFA following ANSES nomenclature.

- Total MUFA, including oleic acid (18:1n-9 cis), the main MUFA in the $n$-9 family.

- Total PUFA including $\alpha$-linolenic acid (18:3n-3 c9, c12, c15) (ALA), DHA (22:6n-3 c4,c7, c10,c13,c16, c19) and EPA (20:5n-3c5,c8,c11,c14,c17c) from the $n-3$ family and linoleic acid (18:2n-6c9,c12) (LA) and arachidonic acid (20:4n-6 c5, $c 8, c 11, c 14)$ (AA) from the $n-6$ family.

Trans-FA could not be analysed, as they were not included in the Ciqual 2013 database, not considered by the ANSES as a national health issue.

\section{Quality of data}

As the process of matching up the product names used in the two databases has not been completed, techniques for dealing with the missing values were applied for 149 of the 1342 food products having no direct correspondence. For 137 of them, we allocated values of food being very close in terms of compositions (e.g. 'olive oil added to cooking' has been assigned values of 'virgin olive oil', unique olive oil reference in the INCA 2 nomenclature). For the remaining eleven foods (the last being the 'uncodified food' that is excluded from our analysis), we used values of Ciqual 2008 when food nomenclature was available, and for those not available we calculated the average value of the food subgroup using Ciqual 2008 data.

\section{Recommended fatty acid intake}

The mean French population intakes were compared with the recommended intake levels and ranges for total fat and FA for adults as established by ANSES: total fat 35-40 \%EIEA, total SFA $<12 \%$ EIEA, specific SFA (lauric, myristic and palmitic acids) $<8 \%$ EIEA, ALA $1 \%$ EIEA, linolenic acid $4 \%$ EIEA, oleic acid 15-20\%EIEA, DHA $250 \mathrm{mg} / \mathrm{d}$, and EPA $250 \mathrm{mg} / \mathrm{d}^{(14)}$.

\section{Fat adherence score}

To investigate the extent to which FA intakes deviated from recommendations and consequently from potential cardiovascular benefits, a weighted fat adherence score was created combining the intakes of the different FA and their relative weight in a perspective of CVD prevention. The individual scores were computed in relation to the recommended daily intakes, with a ranking of 0 to 4 , where 4 represents the highest adherence to guidelines and 0 represents the lowest:

- for SFA: <8 \%EIEA (coded 4), 8-10 \%EIEA (3), 10-12 \%EIEA (2), 12-14 \%EIEA (1) and >14 \%EIEA (0);

- oleic acid: $<7.5 \%$ EIEA (0), 7.5-10 \%EIEA (1), 10-12.5 \%EIEA (2), 12.5-15 \%EIEA (3) and >15 \%EIEA (4);

- total n-6: <2 \%EIEA (0), 2-4 \%EIEA (1), 4-6 \%EIEA (3) and $>6 \%$ EIEA (4);

- $n-3$ as the maximum between DHA and ALA:

o DHA: $<100 \mathrm{mg} / \mathrm{d}$ (0), 100-200 mg/d (1), 200-250 mg/d (2) and $>250 \mathrm{mg} / \mathrm{d}(4)$;

o ALA: $0-1 \mathrm{~g} / \mathrm{d}(0), 1-2 \mathrm{~g} / \mathrm{d}(2)$ and $>2 \mathrm{~g} / \mathrm{d}(4)$;

- total cholesterol: $<200 \mathrm{mg} / \mathrm{d}$ (0), 200-300 mg/d (1) and $>300 \mathrm{mg} / \mathrm{d}(2)$.

The final score is the combination of the six separated scores, based on the relative weight we estimated for each nutrient on CVD prevention: SFA count for $1 / 3$, PUFA count for $1 / 3$ ( $n-31 / 6$ plus $n-61 / 6)$, and MUFA and cholesterol count for $1 / 6$ each.

\section{Potential explanatory factors}

The following factors were considered as modulators of consumption patterns, and were included as potential explanatory factors for score variations:

- Socio-demographic data (age, sex, region, social category of the household chief, diploma); 
- Alcohol consumption, fish consumption and consumption of different types of margarines including those supplemented with $n$-3 FA;

- Smoking status, BMI or nutritional status, elderly (>75 years), physical activity, reading labels on food products, being informed about nutrition, being on a diet (for medical reason or other reasons) and being on hormonal substitution treatment.

Some of these factors are quite rare in the data but are still of interest regarding our goal of linking FA intakes and specific diseases: diet for diabetes 44/2624, diet for high cholesterol $74 / 2624$ and diet for CVD 32/2624.

\section{Quantitative data analysis}

Daily intakes were computed for each adult and each of the forty-four food groups of the INCA 2 database on the total period of time on which the individuals filled in their consumption ( $7 \mathrm{~d}$ for most of them). The results are expressed in terms of daily intake in $\mathrm{g} / \mathrm{d}$ or $\mathrm{mg} / \mathrm{d}$ when necessary (for EPA, DHA and cholesterol) or as a percentage of EIEA.

All statistical analyses were performed using $\mathrm{R}$ - namely, the Survey package integrating weights in all classical analysis (mean, regression, ANOVA) ${ }^{(15)}$ and the FactoMineR package for multivariate analysis ${ }^{(16)}$. For each intake, basic statistics were computed such as means, standard deviations, percentiles and percentages of data over or below recommended daily intakes.

To evaluate the significance of the differences in intakes by region or education level, the effects of age and sex were taken into account through type II tests, so that age and sex are not confusion factors in the results for region and education levels.

A scaled principal component analysis (PCA) was performed on the detailed FA intakes (eight SFA, one MUFA, five PUFA), using the weights, so that the analysis is representative of the French population. The goal of this multivariate analysis was to identify some structures in the data. The fat adherence score (denoted as d.score in Fig. 2) was added as a supplementary variable, to see how it relates to detailed FA intakes.

A simple ANOVA was run on the fat adherence score against all potential explanatory factors listed in the previous section (still weighting the data as recommended by ANSES). The tests conducted were type II, meaning that in each case when testing the significance of a factor all others factors were included into the model, so that other effects were controlled when considering a given factor.

\section{Results}

The major values of French adults' total fat and FA daily intakes and the French Food Safety Agency RDI levels are shown in Table 1 along with comments below with respect to ANSES recommendations. Summary statistics for detailed FA intakes and detailed FA intakes by age, region and education level are available in the online Supplementary Material.

\section{Total fat}

The mean fat intake of French adults was $38.0 \%$ of the total EIEA (\%EIEA). This figure met the guideline for the RDI defined by the ANSES in 2010 for FA, that is 35-40\%EIEA. A total of $36.1 \%$ French adults met the recommendation, with $29 \cdot 3 \%$ of the French adult population below 35 \%EIEA and $34.5 \%$ over $40 \%$ EIEA.

\section{SFA}

The mean SFA total intake was $14.4 \%$ EIEA, $20 \%$ above the ANSES RDI (12\%EIEA). A broad 5-fold variation was reported across the French adult population between P2.5 and P97.5. Specifically, the three SFA (lauric acid, myristic acid and palmitic acid) accounted for more than $9.5 \%$ EIEA, whereas ANSES recommends that it should not exceed 8 \%EIEA. Only $21.5 \%$ of the population did satisfy this $8 \%$ EIEA recommendation. The mean palmitic acid intake itself reached $7 \cdot 3$ \%EIEA.

\section{MUFA}

The mean daily intake of oleic acid, the main MUFA in the $n-9$ family, was $23.7 \mathrm{~g} / \mathrm{d}$ or $10.8 \%$ EIEA, a low level compared with the RDI (15-20\%EIEA). Large variations were observed as follows: intakes ranged from 8.7 to $43.3 \mathrm{~g} / \mathrm{d}$ (from $\mathrm{P} 2.5$ to P97.5). Only $6 \cdot 8 \%$ of the adults did meet the guideline of 15-20 \%EIEA, with $92 \cdot 3 \%$ being below $15 \%$ EIEA.

\section{PUFA}

The average daily intake of polyunsaturated $n$-3 FA was $0.4 \%$ EIEA for ALA (RDI: 1\%), $137 \mathrm{mg}$ for DHA (RDI: $250 \mathrm{mg}$ ) and $102 \mathrm{mg}$ for EPA (RDI: $250 \mathrm{mg}$ ), with tremendous variations, particularly for long-chain $n$-3 PUFA. Only $14.6 \%$ of the adult population appeared to meet the RDI of $250 \mathrm{mg} / \mathrm{d}$ for DHA, $7 \cdot 8 \%$ for EPA and $7.0 \%$ for both DHA and EPA.

The mean intake of the main polyunsaturated $n-6$ FA, LA, was $8.4 \mathrm{~g} / \mathrm{d}$ and 3.9 \%EIEA. This value met the ANSES RDI (4 \%EIEA) in $65.1 \%$ of the population. The low ALA intake translated into a mean LA:ALA ratio of 9.6, whereas the ANSES recommendation is $<5 ; 95 \%$ of the adult population had a ratio exceeding 5 .

\section{Cholesterol}

For French adults, the mean dietary cholesterol intake was $304 \mathrm{mg} / \mathrm{d}$. Intakes varied from $112(\mathrm{Q} 2 \cdot 5)$ to $563 \mathrm{mg} / \mathrm{d}(\mathrm{Q} 97 \cdot 5)$. About $50 \%$ of adult population had mean cholesterol intakes below $300 \mathrm{mg} / \mathrm{d}$. The correlation between cholesterol intake and SFA intake was strong ( $r 0.72)$, and was milder with MUFA $(r 0.61)$ and PUFA ( $r 0.44)$.

\section{Food categories contributions}

Different food categories with major contribution to FA intakes are reported in Table 2 .

The major contributors to total FA intakes were cheese and butter (19\%) with a similar weight ( 9.6 and $9.4 \%$, respectively) as well as oil with a contribution of $12 \%$ to total FA. 
Table 1. Mean daily intake of the French adult population (INCA 2-Ciqual)

(Mean values and standard deviations; 2.5 th and 97.5 th percentiles; percentages and $95 \%$ confidence intervals)

\begin{tabular}{|c|c|c|c|c|c|c|c|c|c|}
\hline & \multicolumn{4}{|c|}{ Mean daily intake INCA 2} & & & & \multirow{3}{*}{$\begin{array}{c}\text { Population percentage } \\
\text { meeting the RDI }\end{array}$} & \multirow[b]{3}{*}{$95 \% \mathrm{Cl}(\%)$} \\
\hline & \multicolumn{2}{|c|}{ Daily intake } & \multicolumn{2}{|c|}{ Percentage of EIEA } & \multicolumn{2}{|c|}{ Lowest and highest intake (\%EIEA) } & & & \\
\hline & Mean & SD & Mean & SD & 2.5th percentile & 97.5th percentile & ANSES RDI & & \\
\hline \multicolumn{10}{|l|}{ Fat } \\
\hline $\begin{array}{l}\text { Total fat } \\
\text { SFA }\end{array}$ & $83.0 \mathrm{~g}$ & $27 \cdot 3 \mathrm{~g}$ & $38 \cdot 0$ & $5 \cdot 7$ & $26 \cdot 8$ & $49 \cdot 1$ & $35-40 \%$ & $36 \cdot 1$ & $34 \cdot 3,37 \cdot 9$ \\
\hline Total SFA & $31.8 \mathrm{~g}$ & $12 \cdot 1 \mathrm{~g}$ & 14.4 & 3.0 & 8.5 & $20 \cdot 6$ & $\leq 12 \%$ & $21 \cdot 6$ & $20,23 \cdot 2$ \\
\hline Specific* SFA & $20.9 \mathrm{~g}$ & $8.0 \mathrm{~g}$ & 9.5 & $2 \cdot 0$ & $5 \cdot 6$ & $13 \cdot 3$ & $\leq 8 \%$ & 21.5 & $19 \cdot 9,23 \cdot 1$ \\
\hline Palmitic & $16 \cdot 1 \mathrm{~g}$ & $5.9 \mathrm{~g}$ & $7 \cdot 3$ & 1.4 & 4.5 & 9.9 & ND & ND & \\
\hline \multicolumn{10}{|l|}{ MUFA } \\
\hline Total MUFA & $29.9 \mathrm{~g}$ & $10.4 \mathrm{~g}$ & $13 \cdot 3$ & $3 \cdot 0$ & 8.4 & $19 \cdot 7$ & ND & ND & \\
\hline Oleic acid & $23.7 \mathrm{~g}$ & $9.0 \mathrm{~g}$ & $10 \cdot 8$ & $2 \cdot 8$ & $6 \cdot 3$ & $17 \cdot 0$ & $15-20 \%$ & $6 \cdot 8$ & $5 \cdot 8,7 \cdot 8$ \\
\hline \multicolumn{10}{|l|}{ PUFA } \\
\hline Total PUFA & $12.4 \mathrm{~g}$ & $5.6 \mathrm{~g}$ & $5 \cdot 7$ & $2 \cdot 0$ & $3 \cdot 0$ & $10 \cdot 6$ & ND & ND & \\
\hline $\operatorname{ALA}(n-3)$ & $0.9 \mathrm{~g}$ & $0.5 \mathrm{~g}$ & 0.4 & 0.2 & 0.2 & 0.9 & $1 \% †$ & $2 \cdot 3$ & $1 \cdot 7,2 \cdot 9$ \\
\hline $\mathrm{DHA}(n-3)$ & $137 \mathrm{mg}$ & $139 \mathrm{mg}$ & 0.06 & 0.06 & 0.00 & 0.23 & $250 \mathrm{mg} \ddagger$ & $14 \cdot 6$ & $13 \cdot 2,16$ \\
\hline EPA $(n-3)$ & $102 \mathrm{mg}$ & $111 \mathrm{mg}$ & 0.05 & 0.05 & 0.01 & $0 \cdot 17$ & $250 \mathrm{mg} \ddagger$ & $7 \cdot 8$ & $6 \cdot 8,8 \cdot 8$ \\
\hline LA $(n-6)$ & $8.4 \mathrm{~g}$ & $4.4 \mathrm{~g}$ & 3.9 & 1.7 & $1 \cdot 8$ & $8 \cdot 2$ & $4 \% \S$ & $65 \cdot 1$ & $63 \cdot 3,66 \cdot 9$ \\
\hline
\end{tabular}

EIEA, energy intake excluding alcohol; ANSES, French Agency for Food, Environmental and Occupational Health \& Safety; RDI, recommended dietary intakes; ALA, $a$-linolenic acid; LA, linoleic acid.

* Lauric acid, myristic acid and palmitic acid.

$\dagger$ Considered as $\geq 1 \%$ for the calculation of percentage meeting the RDI.

¥ Considered as $\geq 250 \mathrm{mg}$ for the calculation of percentage meeting the RDI.

$\S$ Considered as $\leq 4 \%$ for the calculation of percentage meeting the RDI.

Table 2. Main food groups contributing to fatty acid intake in French adults

\begin{tabular}{|c|c|}
\hline Fatty acids & Main contributors (\% of total fatty acid intake) \\
\hline Total fatty acids & Oil $(12 \%)$; cheese $(9.6 \%)$; butter $(9.4 \%)$; delicatessen (7.6\%); unprocessed meat ( $6.3 \%)$ \\
\hline SFA & Animal fats $(43.5 \%)$ including butter $(14.7 \%)$, cheese $(14.8 \%)$, delicatessen $(7 \%)$ and meat $(7 \%)$; pastries and cakes $(6.4 \%)$ \\
\hline Specific SFA & Animal fats $(42.0 \%)$ including cheese $(14.5 \%)$, butter $(13.9 \%)$, delicatessen $(7 \%)$ and meat $(6.6 \%)$; pastries and cakes $(7.6 \%)$ \\
\hline MUFA & Animal fats $(29.7 \%)$ including delicatessen $(9.3 \%)$, cheese $(7.2 \%)$, meat $(7 \%)$ and butter $(6.2 \%)$; oil $(17.3 \%)$ \\
\hline DHA & Fish (54.6\%); eggs (11.2\%); poultry and game $(7.9 \%)$ \\
\hline EPA & Fish (48.1\%); seafood $(5.4 \%)$; meat $(5.2 \%)$ \\
\hline$a$-Linolenic acid & Pastries and cakes (11.2\%); oil (9.7\%); condiments and sauces (9.5\%); mixed dishes $(5.8 \%)$ \\
\hline Linoleic acid & Oil $(20.7 \%)$; condiments and sauces $(12.6 \%)$; mixed dishes $(6.9 \%)$; delicatessen $(6.5 \%)$ \\
\hline Arachidonic acid & $\begin{array}{l}\text { Animal fats }(51.4 \%) \text { including delicatessen }(20.5 \%) \text {, meat }(15.8 \%) \text {, poultry and game }(15.1 \%) \text {; pastries and cakes }(12.9 \%) \text {; } \\
\text { fish }(8.6 \%)\end{array}$ \\
\hline Cholesterol & $\begin{array}{l}\text { Animal fats }(44.4 \%) \text { including eggs and derivatives }(14.8 \%) \text {, meat }(11.9 \%) \text {, poultry and game }(9.3 \%) \text {, delicatessen }(8.4 \%) \text {; } \\
\text { mixed dishes }(8 \%)\end{array}$ \\
\hline
\end{tabular}

Regarding SFA, the main contributions were animal fats (43.5\%), particularly butter (14.7\%) and cheese (14.8\%).

For MUFA, the main source was oil (17.3\%) followed by animal fats $(29.7 \%)$ : butter $(6 \cdot 2 \%)$, cheese $(7 \cdot 2 \%)$, meat products $(9.3 \%)$ and meat $(7 \%)$.

For $n$ - 3 PUFA, the main contributor of DHA and EPA was fish ( 54.6 and $48.1 \%$, respectively), and ALA intake was from pastries and cakes (11.2\%), oil (9.7\%), and condiments and sauces (9.5\%).

For $n-6$ PUFA, oil was again the main contributor, especially for LA $(20.5 \%)$.

\section{Differences in intakes by sex, age, education level and region}

Overall, in the French adult population, we observed influences of sex, age, level of education and region on FA intake.
Detailed results are available in the online Supplementary Material; only the main findings are described below.

Regarding age, intake of PUFA increased with age significantly only in men. $n$-3 FA intakes increased with age for both men and women. Among SFA, only capric acid intake increased significantly with age and only in men.

Intakes of oleic acid and n-3 PUFA (EPA, DHA and ALA) increased with French level of education.

With regard to regional consumption, lauric acid presented a significantly higher intake in the north-west part of France than in the south, whereas intakes of oleic acid and more generally of MUFA were higher in the south. The most significant regional differences were essentially observed for PUFA. Intake of $n$-3 PUFA (EPA and DHA) was higher in Paris area and in the west and south-west regions, whereas $n$ - 6 PUFA intakes were higher in the south. 


\section{Analysis of the fat adherence score}

Fig. 1 shows the distribution of the fat adherence score: it was mildly skewed to the right with a mean of 1.43 (SD 0.57) and median of 1.33 , ranging from $0.5(\mathrm{P} 2.5)$ to 2.67 (P97.5).

The PCA performed on all individual FA (Fig. 2) resulted in three principal components (totalising $54 \cdot 8+14 \cdot 8+10 \cdot 3=79 \cdot 9 \%$ of the data inertia). The first component was mainly driven by SFA (specific SFA), the second component by MUFA and the third one mostly by EPA and DHA (fish consumption). On the basis of position of the fat adherence score on the correlation circle (added as a supplementary variable), it is clear that individuals with high scores had higher EPA and DHA intakes (positive correlation) and lower SFA intakes (negative correlation).

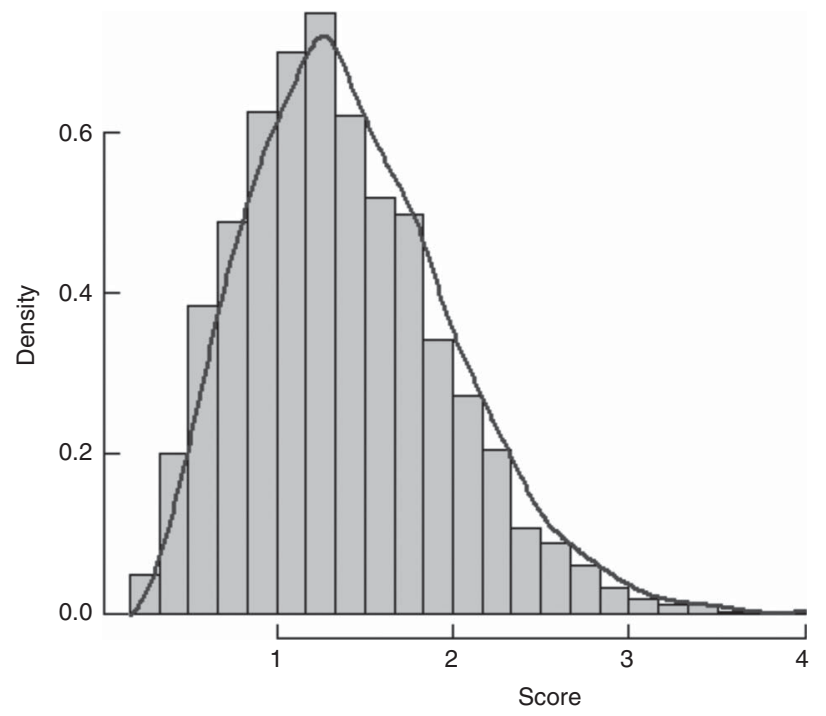

Fig. 1. Distribution of the fat adherence score. The score is between 0 (poor quality lipid diet) and 4 (optimal lipid diet) by construction.
Table 3 gives the factors in decreasing order of importance, based on a simple ANOVA that was run on the score against all available factors.

Regarding the direction of effects, we observed that the higher the fish consumption is, the higher the score is; the south of France had higher scores, as consuming margarines supplemented with $n$ - 3 FA (essentially ALA) increased the score as well as being a woman. Higher alcohol intakes were

Table 3. Multivariable analysis of the factors with influence on the score of healthy lipid diet according to French Agency for Food, Environmental and Occupational Health \& Safety French recommended dietary intakes 2010‡

\begin{tabular}{|c|c|c|}
\hline Factors & $P$ & Significance \\
\hline Consumption of fish ( 3 modalities) & $1 \cdot 16 \mathrm{E}-18$ & $\star \star \star *$ \\
\hline Region (8 modalities) & 4.02E-09 & 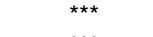 \\
\hline Consumption of supplemented margarine & $2 \cdot 66 \mathrm{E}-07$ & 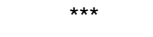 \\
\hline Sex & $2 \cdot 08 \mathrm{E}-04$ & $\star \star \star ~$ \\
\hline Consumption of alcohol (3 modalities) & $9 \cdot 64 \mathrm{E}-04$ & 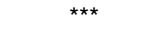 \\
\hline Diet for cholesterol & $1.36 \mathrm{E}-03$ & $\star \star$ \\
\hline Being on a diet & $6 \cdot 04 \mathrm{E}-03$ & ** \\
\hline Socio-professional category (8 modalities) & $2 \cdot 01 \mathrm{E}-02$ & * \\
\hline Type of agglomeration (5 modalities) & $3 \cdot 47 \mathrm{E}-02$ & * \\
\hline Being on hormonal substitution treatment & $8 \cdot 91 \mathrm{E}-02$ & $\dagger$ \\
\hline Reading labels (3 modalities) & $1 \cdot 12 \mathrm{E}-01$ & NS \\
\hline Consumption of standard margarine & $1 \cdot 23 \mathrm{E}-01$ & NS \\
\hline Interest in health & $1.48 \mathrm{E}-01$ & NS \\
\hline Consumption of light margarine & $1 \cdot 62 \mathrm{E}-01$ & NS \\
\hline Physical activity index (3 modalities) & $1 \cdot 70 \mathrm{E}-01$ & NS \\
\hline Interest in nutrition & $1 \cdot 83 \mathrm{E}-01$ & NS \\
\hline Smoking (5 modalities) & $3 \cdot 34 \mathrm{E}-01$ & NS \\
\hline Diet for CVD & $3 \cdot 69 \mathrm{E}-01$ & NS \\
\hline Diploma (5 modalities) & $4 \cdot 31 \mathrm{E}-01$ & NS \\
\hline Age (3 modalities) (years) & $4 \cdot 72 \mathrm{E}-01$ & NS \\
\hline Being older than 75 years & $4 \cdot 75 \mathrm{E}-01$ & NS \\
\hline BMI (4 modalities) & $4 \cdot 94 \mathrm{E}-01$ & NS \\
\hline Being on a diet for diabetes & $6 \cdot 27 E-01$ & NS \\
\hline
\end{tabular}

${ }^{\star} P<0.05,{ }^{\star *} P<0.01,{ }^{\star * \star} P<0.001$.

$\dagger P<0.1$.

$\ddagger$ The adjusted $R^{2}$ is 0.156 . (a)

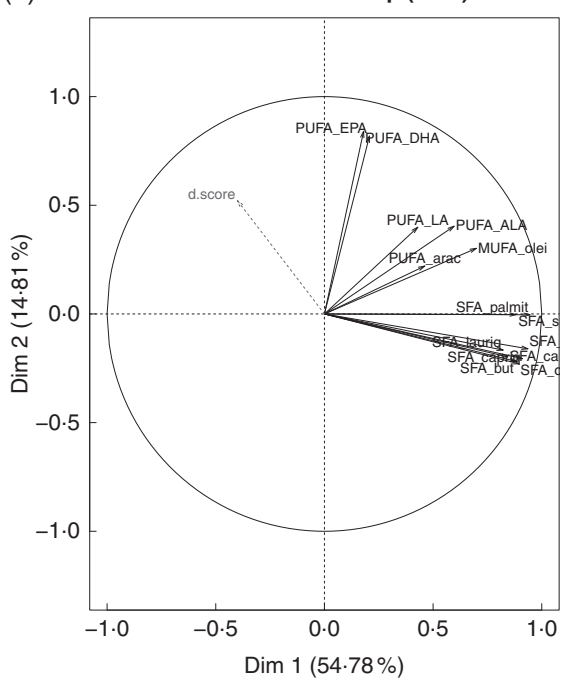

(b)

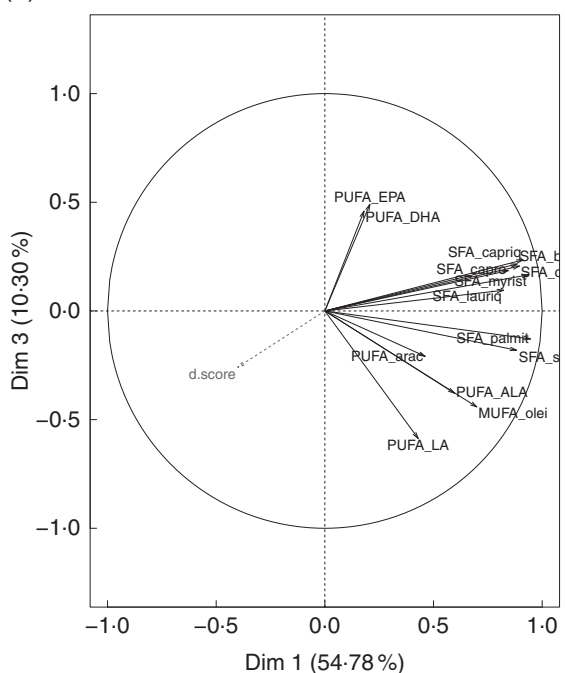

(c)

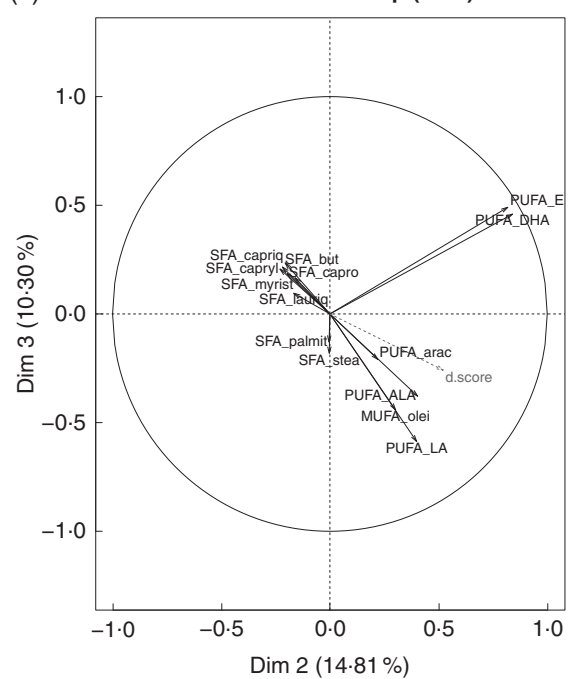

Fig. 2. Correlation circles from principal component analysis (PCA) analysis on weighted data (d.score is the fat adherence score). ALA, $a$-linolenic acid; LA, linoleic acid; arac, arachidonic acid; stea, stearic acid; lauriq, lauric acid; olei, oleic acid; palmit, palmitic acid; myrist, myristic acid; capriq, capric acid; capryl, caprylic acid; capro, caproic acid; but, butyric acid. 
associated with lower scores (high consumption: 1.37 (SD 0.03); moderate consumption: 1.46 (SD 0.02); no consumption: 1.48 (sD 0.03); $P=9.64 \mathrm{e}-4$ ). Being on a hypocholesterolaemic diet led to higher scores (1.88 (SD 0.09) v. 1.42 (SD 0.01); $P=1.36 \mathrm{e}-3)$; conversely, scores of people following a diet for diabetes (1.59 (SD 0.08) v. 1.44 (SD 0.01); NS) or CVD (1.69 (SD 0.15) v. 1.43 (SD 0.01); NS) were similar to controls.

\section{Discussion}

Data from this large INCA 2 survey in the French population show a significantly elevated intake of SFA and a low intake of MUFA and $n-3$ PUFA $v$. current French recommendations ${ }^{(17)}$. This high SFA intake remains mostly because of consumption of butter and cheese. $n$-3 PUFA intake is related to low levels of fish consumption. Furthermore, we found by using a weighted score of healthy lipid intake (fat adherence score) that an optimal FA intake is positively associated with consumption of fish and sources of $n-3$ FA, living in the south of France, being female, and having a higher education level, whereas alcohol consumption was associated with poor FA intake.

An important finding of this survey is the persistently high level of SFA intake in the French population (14.4\%), which is in the higher ranges of SFA intake compared with other population surveys $^{(10,12)}$. In agreement, Eilander et $a l^{(10)}$ in a previous combined analysis of different European studies reported a range of SFA intake from $8.9 \%$ in Portugal to $15.5 \%$ in France of total energy intake. Comparable high SFA intake levels are reported in the USA ${ }^{(18,19)}$. Our detailed analysis on food consumption indicates that this elevated French SFA intake is mainly due to a high consumption of cheese and butter, including the three SFA pointed out by ANSES (lauric, myristic and palmitic). These results suggest that national educational cardiovascular prevention programmes relative to food consumption should focus more on these food items in order to reduce SFA intake in the French population. This is a challenge in a country where cheese is a cultural food having a particular place in the diet and a major source for micronutrients such as $\mathrm{Ca}$ and vitamin $\mathrm{D}^{(20)}$.

Although the observed $n$ - 6 LA mean intake level almost met the ANSES recommendation, the low $n$ - 3 PUFA intake level is another important piece of information in our survey, with a value far below the French Agency recommended intake. As indicated by data on foods consumption, this low $n-3$ PUFA level is mainly because of a low level of fish consumption. Interests of $n$-3 PUFA in cardiovascular prevention have been widely studied ${ }^{(7,21-23)}$. Long-chain EPA and DHA have positive effects on many cardiovascular markers, and consumption of fish and seafood $n-3$ PUFA is associated with lower CHD death ${ }^{(24)}$. Recommendation of two servings of fish per week remains a strong one both in primary and in secondary prevention ${ }^{(25)}$. Our present data showing both low levels of fish consumption in the French population and its pivotal role on EPA and DHA intakes must reinforce our advice for fish consumption in the general population. French SFA intake level is also high and replacing SFA with PUFA, including those from non-hydrogenated vegetable oil sources (ALA as well as LA), may be an efficient option in terms of cardioprotection objectives $^{(9,26)}$. As a consequence, practical recommendations to the general population should not only be on limiting intakes of animal SFA but also on promoting consumption of PUFA fat from plant sources and/or complex carbohydrates.

We also show that MUFA intake is significantly under the recommended level. Although data on the benefit of MUFA intake on CVD prevention have been challenged ${ }^{(27,28)}$, many studies have reported a beneficial effect of a Mediterranean diet rich in MUFA on CVD ${ }^{(29,30)}$. According to our data, the relatively low consumption of oleic acid is the leading factor responsible for the low MUFA intake in the French population. Living in the south of France is associated with a better FA intake, this is likely due to a higher consumption of oleic acid with frequent use of olive oil, specifically in this part of France.

In this study, the ANSES recommendations were used as reference, being the one communicated to the French population in a perspective of public health. Several international organisations produce fat intake recommendations, based on various types of criteria and evidence, leading to different values of RDI. As an example, the WHO recommends $20-35 \%$ of total energetic intake (EI) for total fat and the Dietary Guidelines for Americans (DGA) recommend 25-35 \%EI compared with 35-40 \%EIEA for ANSES ${ }^{(31,32)}$. These apparently more stringent recommendations are actually satisfied for $99.9 \%$ (WHO) and $98.1 \%$ (DGA) of our sample, because of the expression as \%EI of these recommendations compared with \%EIEA for ANSES.

Using a fat adherence score, we have been able to show that some factors such as consumption of fish and margarines supplemented with PUFA, living in the south of France, female sex and higher education level are associated with a better FA intake, whereas alcohol consumption is associated with a poor FA intake. The fact that consumption of fish and margarines supplemented with PUFA is associated with optimal fatty intake is consequently in line with the national recommendations. Female sex was also associated with a better FA intake. We assume that females are more interested and concerned about food information. Accordingly, a higher education level is also another factor associated with a better FA intake. This point has also been reported in previous studies ${ }^{(33)}$. One possible explanation is that educated people are more concerned about diet, good health and CVD prevention. The fact that alcohol consumption was associated with a bad FA intake is an interesting piece of information in a country where the French paradox has been putatively conferred to alcohol consumption.

The ageing of INCA 2 data (10 years) is a limitation of the interpretation of our results. To estimate whether they are still representative of the current consumption of French adults, we considered the CRÉDOC (Research Center for the Study and Observation of Living), studies that regularly collect consumer data in France, their most recent campaign dating from 2013. These data do not suggest a change in consumer trends over the last decade (unpublished results).

In conclusion, INCA 2 data indicate that French adults have SFA intakes persistently higher than ANSES national recommendations, combined with very inadequate intakes of PUFA, $n-3$ and MUFA. This situation is quite similar to what is observed in other developed countries such as the USA, where most Americans exceed the recommendations for SFA and about 
three-fourth of the population has an eating pattern that is low in vegetable oils. This situation appears unfavourable in terms of cardiovascular prevention and should encourage the French authorities and health professionals to communicate more broadly and more efficiently to the general public in order to reverse this imbalance in dietary FA.

\section{Acknowledgements}

We thank French ANSES and Ciqual for providing public and open source data that were used in this study.

Note: At the end of 2015, ANSES issued a report on the fatty acid intake of the French population living in France, based on the INCA 2 consumption study data and an internal unpublished updated version of the Ciqual composition table ${ }^{(34)}$. Reported intake levels are strictly comparable with those presented in this study, with the exception of a slightly superior AA intake (0.07\%EIEA in ANSES report $v .0 .05 \%$ EIEA in our results), due to modified composition data in eggs and derived products

The statistical analyses presented in this manuscript were funded by Terres Univia, the interbranch organisation representing the interests of French vegetable oils and proteins.

J. T. processed the statistical analyses and co-wrote the manuscript; P. M., B. V. and S. P. co-wrote the manuscript; C. L. G. and N. S. reviewed the manuscript and provided critical feedback.

S. P. is a consulting with Terres Univia; C. L. G. and N. S. work with Terres Univia; P. M. has no conflict of interest to report with the food industry.

\section{Supplementary material}

For supplementary material/s referred to in this article, please visit https://doi.org/10.1017/S000711451600413X

\section{References}

1. Hammad S, Pu S \& Jones PJ (2015) Current evidence supporting the link between dietary fatty acids and cardiovascular disease. Lipids 51, 507-517.

2. Harris W (2010) Omega-6 and omega-3 fatty acids: partners in prevention. Curr Opin Clin Nutr Metab Care 13, 125-129.

3. Schwab U, Lauritzen L, Tholstrup T, et al. (2014) Effect of the amount and type of dietary fat on cardiometabolic risk factors and risk of developing type 2 diabetes, cardiovascular diseases, and cancer: a systematic review. Food Nutr Res 58, 25145.

4. Willett WC (2012) Dietary fats and coronary heart disease. J Intern Med 272, 13-24.

5. Anand SS, Hawkes C, de Souza RJ, et al. (2015) Food consumption and its impact on cardiovascular disease: importance of solutions focused on the globalized food system: a report from the workshop convened by the World Heart Federation. J Am Coll Cardiol 66, 1590-1614.

6. Lim SS, Vos T, Flaxman AD, et al. (2012) A comparative risk assessment of burden of disease and injury attributable to 67 risk factors and risk factor clusters in 21 regions, 1990-2010: a systematic analysis for the Global Burden of Disease Study 2010. Lancet 380, 2224-2260.
7. Michas G, Micha R \& Zampelas A (2014) Dietary fats and cardiovascular disease: putting together the pieces of a complicated puzzle. Atherosclerosis 234, 320-328.

8. Nettleton JA, Villalpando S, Cassani RSL, et al. (2013) Health significance of fat quality in the diet. Ann Nutr Metab 63 , 96-102.

9. Mozaffarian D, Micha R \& Wallace S (2010) Effects on coronary heart disease of increasing polyunsaturated fat in place of saturated fat: a systematic review and meta-analysis of randomized controlled trials. PLoS Med 7, e1000252.

10. Eilander A, Harika RK \& Zock PL (2015) Intake and sources of dietary fatty acids in Europe: are current population intakes of fats aligned with dietary recommendations? Eur J Lipid Sci Technol 117, 1370-1377.

11. Harika RK, Cosgrove MC, Osendarp SJM, et al. (2011) Fatty acid intakes of children and adolescents are not in line with the dietary intake recommendations for future cardiovascular health: a systematic review of dietary intake data from thirty countries. Br J Nutr 106, 307-316.

12. Harika RK, Eilander A, Alssema M, et al. (2013) Intake of fatty acids in general populations worldwide does not meet dietary recommendations to prevent coronary heart disease: a systematic review of data from 40 countries. Ann Nutr Metab 63, 229-238.

13. Honors MA, Harnack LJ, Zhou X, et al. (2014) Trends in fatty acid intake of adults in the Minneapolis-St Paul, MN metropolitan area, 1980-1982 through 2007-2009. J Am Heart Assoc 3, e001023.

14. Agence Française de Sécurité Sanitaire des Aliments (AFSSA) (2010) Avis de l'Agence française de sécurité sanitaire des aliments relatif à l'actualisation des apports nutritionnels conseillés pour les acides gras (Opinion of the French Food Safety Agency on the Update of French Population Reference Intakes (RDIs) for Fatty Acids). Request no. 2006-SA-0359.

15. Lumley T (2004) Analysis of complex survey samples. J Stat Softw 9, v009i08.

16. Lê S, Josse J \& Husson F (2008) FactoMineR: an R package for multivariate analysis. J Stat Softw 25, 1-18.

17. Dubuisson C, Lioret S, Touvier M, et al. (2010) Trends in food and nutritional intakes of French adults from 1999 to 2007: results from the INCA surveys. Br J Nutr 103, 1035-1048.

18. Micha R, Khatibzadeh S, Shi P, et al. (2014) Global, regional, and national consumption levels of dietary fats and oils in 1990 and 2010: a systematic analysis including 266 countryspecific nutrition surveys. BMJ 348, g2272.

19. Slining MM \& Popkin BM (2013) Trends in intakes and sources of solid fats and added sugars among US children and adolescents: 1994-2010. Pediatr Obes 8, 307-324.

20. Coudray B (2011) The contribution of dairy products to micronutrient intakes in France. J Am Coll Nutr 30, 410S-414S.

21. Chowdhury R, Warnakula S, Kunutsor S, et al. (2014) Association of dietary, circulating, and supplement fatty acids with coronary risk: a systematic review and meta-analysis. Ann Intern Med 160, 398-406.

22. Khawaja OA, Gaziano JM \& Djoussé L (2014) N-3 fatty acids for prevention of cardiovascular disease. Curr Atheroscler Rep 16, 450 .

23. de Souza RJ, Mente A, Maroleanu A, et al. (2015) Intake of saturated and trans unsaturated fatty acids and risk of all cause mortality, cardiovascular disease, and type 2 diabetes: systematic review and meta-analysis of observational studies. BMJ 351, h3978.

24. Zheng J, Huang T, Yu Y, et al. (2012) Fish consumption and CHD mortality: an updated meta-analysis of seventeen cohort studies. Public Health Nutr 15, 725-737. 
25. Gil A \& Gil F (2015) Fish, a Mediterranean source of $n$-3 PUFA: benefits do not justify limiting consumption. Br J Nutr 113, Suppl. 2, S58-S67.

26. Mensink RP, Zock PL, Kester ADM, et al. (2003) Effects of dietary fatty acids and carbohydrates on the ratio of serum total to HDL cholesterol and on serum lipids and apolipoproteins: a meta-analysis of 60 controlled trials. Am J Clin Nutr 77, 1146-1155.

27. Schwingshackl L \& Hoffmann G (2014) Association of dietary, circulating, and supplement fatty acids with coronary risk. Ann Intern Med 161, 455-456.

28. Schwingshackl L \& Hoffmann G (2014) Monounsaturated fatty acids, olive oil and health status: a systematic review and meta-analysis of cohort studies. Lipids Health Dis 13, 154 .

29. Gillingham LG, Harris-Janz S \& Jones PJH (2011) Dietary monounsaturated fatty acids are protective against metabolic syndrome and cardiovascular disease risk factors. Lipids $\mathbf{4 6}$, 209-228.

30. Guasch-Ferré M, Babio N, Martínez-González MA, et al. (2015) Dietary fat intake and risk of cardiovascular disease and all-cause mortality in a population at high risk of cardiovascular disease. Am J Clin Nutr 102, 1563-1573.

31. Food and Agriculture Organization (2010) Fats and fatty acids in human nutrition. Report of an expert consultation. FAO Food Nutr Pap 91, 1-166.

32. Millen BE, Abrams S, Adams-Campbell L, et al. (2016) The 2015 dietary guidelines advisory committee scientific report: development and major conclusions. Adv Nutr Bethesda Md 7, 438-444.

33. Woo J, Leung SS, Ho SC, et al. (1999) Influence of educational level and marital status on dietary intake, obesity and other cardiovascular risk factors in a Hong Kong Chinese population. Eur J Clin Nutr 53, 461-467.

34. French Agency for Food, Environmental and Occupational Health \& Safety (2015) AVIS et rapport de l'ANSES relatifs aux «Apports en acides gras de la population vivant en France. Comparaison aux apports nutritionnels conseillés définis en 2010» (Opinion and report of ANSES on 'Intakes of fatty acids of the population living in France. Comparison with the nutritional recommendations defined in 2010'). https:// www.anses.fr/fr/system/files/NUT2014sa0117Ra.pdf (accessed December 2015). 